Check for updates

Cite this: RSC Adv., 2019, 9, 10100

\title{
Assessment of the toxicity and biodegradation of amino acid-based ionic liquids $\uparrow$
}

\author{
Shuanggen Wu, ${ }^{\mathrm{b}}$ Fenfang Li, ${ }^{\mathrm{b}}$ Liangbin Zeng, ${ }^{\mathrm{a}}$ Chaoyun Wang, ${ }^{\mathrm{a}}$ Yuanru Yang ${ }^{\mathrm{a}}$ \\ and Zhijian Tan (1D)*a
}

Amino acid-based ionic liquids (AAILs) are generally thought of as green solvents and widely used in many regions without systematic assessment of their effect on the environment or human health. In this work, a series of AAILs with different cations and amino acid anions were prepared and characterized, after which their microbial toxicity, phytotoxicity, and biodegradability were evaluated. The results showed that not all AAILs had low toxicity against microorganisms and that some AAILs were highly toxic towards the targeted microorganisms. The phytotoxic effect of the AAILs on rice (Oryza sativa L.) further demonstrated that AAILs should not be presumed to be non-toxic to plants. Moreover, the biodegradability tests showed that majority of AAILs were not satisfactorily biodegradable. In summary, not all AAILs are non-toxic or biodegradable, and their effect on the environment and human health must be assessed before their mass preparation and application.

Received 20th August 2018

Accepted 26th March 2019

DOI: 10.1039/c8ra06929h

rsc.li/rsc-advances

and cells. ${ }^{21}$ ILs biodegradability has been evaluated using standardized assays approved by the Organization for Economic Cooperation and Development (OECD) and the International Organization for Standardization (ISO), such as the dissolved organic carbon die-away test (OECD 301A), closed-bottle test (OECD 301D), and $\mathrm{CO}_{2}$ headspace test (ISO 14593). ${ }^{22}$ Most studies proved that the assumption that ILs are "green solvents" is incorrect. Moreover, researchers found that some ILs did not conform to the principle of "green chemistry" since they exhibited higher toxicity than the common volatile organic compounds such as methanol and dichloromethane and had low biodegradability. ${ }^{23}$ In response, ILs containing cations and anions from natural sources, such as choline, ${ }^{24}$ mandelic acid, ${ }^{25}$ betaine,${ }^{26}$ sugars,${ }^{27}$ and amino acids ${ }^{28}$ have attracted increasing attention on the theory that they would be less toxic and more biodegradable.

Natural amino acids can be converted into both cations and anions for the preparation of amino acid-based ionic liquids (AAILs). ${ }^{23,29}$ The most widely used AAILs contain amino acid anions, because these are simple to be produced using an acidbase neutralization reaction. ${ }^{23}$ AAILs possess not only the unique physiochemical properties of traditional ILs, but also show lower toxicity and better biodegradability. ${ }^{30}$ Moreover, amino acids are abundant and cheap biomolecules, which reduces the cost of IL synthesis. ${ }^{30}$ Today, AAILs are considered to be "environmentally-friendly" solvents that can be used for diverse applications, including biomass pretreatment, ${ }^{31}$ as catalysts in organic reactions, ${ }^{32}$ and $\mathrm{CO}_{2}$ capture. ${ }^{33}$

The (eco)toxicity and biodegradation of some AAILs towards microorganisms, green algae, and cells have been evaluated in recent years, ${ }^{34,35}$ and the majority of AAILs were found to have lower toxicity than the original ILs. However, if all AAILs are to

${ }^{a}$ Institute of Bast Fiber Crops, Center of Southern Economic Crops, Chinese Academy of Agricultural Sciences, Changsha 410205, China. E-mail: tanzhijian@caas.cn; tanzhijiantgzy2010@aliyun.com

${ }^{b}$ College of Chemistry and Chemical Engineering, Central South University, Changsha 410083, China

$\dagger$ Electronic supplementary information (ESI) available: Includes additional antimicrobial screening results and characterization of the ionic liquids (FT-IR spectroscopy and ${ }^{1}$ H NMR). See DOI: 10.1039/c8ra06929h 
be labeled "environmentally-friendly", then further assessments are needed. The toxicity and biodegradability of AAILs made up of amino acid anions and different cations, such as cholinium, imidazolium, pyrrolidinium, piperidinium, quaternary ammonium, and quaternary phosphonium, may be different. For example, Hou et $a l .{ }^{36}$ synthesized 18 choline amino acid ionic liquids ([Cho][AA]) and assessed their effects on enzymes, bacteria and biodegradability. They found that [Cho][AA] ILs had low toxicity and good biodegradability due to the choline cation. In contrast, when the cytotoxicity of AAILs composed of alkylimidazolium cations and amino acids towards CaCo- 2 and NIH/3T3 cells was assessed, the researchers found that the AAILs showed biologically unsafe behavior and that their cytotoxicity was similar to that of the conventional ILs 1-butyl-3-methylimidazolium (L)-lactate chloride and 1-butyl-3-methylimidazolium chloride. ${ }^{30}$ Although some studies on the toxicity or biodegradability of AAILs have been published, ${ }^{13,35,36}$ there is a lack of rigorous and systematic studies. As far as we know, the studies are scarce about the toxicity to microorganisms and plants of AAILs containing different cations. Specifically, the toxicity data for some AAILs, such as [Pyr][Cys], [Pip] [Cys], $\left[\mathrm{N}_{2,2,2,2}\right][\mathrm{Cys}]$ hasn't been obtained. Thus, in this work, nineteen representative AAILs with different cations and amino acid anions were prepared (Fig. 1), and assessed for biodegradability and ecotoxicity towards microorganisms and higher plants. This study aimed to supplement the toxicity data of AAILs and to find "environmentally-friendly" AAILs for use in further studies.

\section{Materials and methods}

\section{Materials and reagents}

The main materials and reagents used for the synthesis of AAILS were L-valine (Val), L-cysteine (Cys), L-aspartic acid (Asp), L-

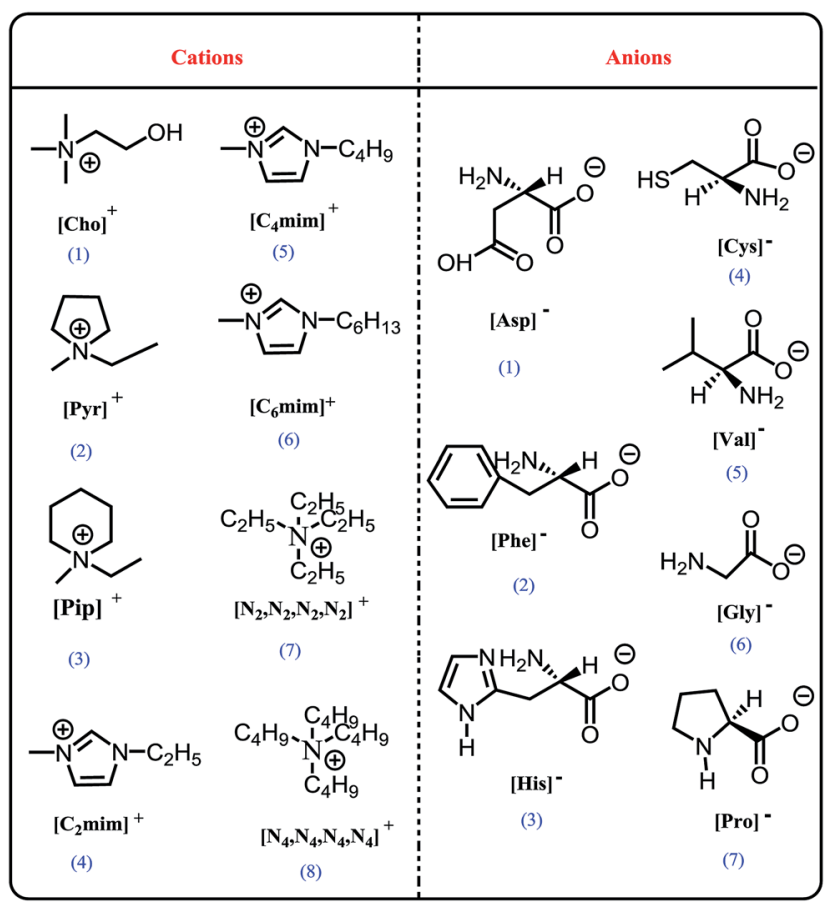

Fig. 1 The cations and anions structures of the AAILs. histidine (His), L-phenylalanine (Phe), L-proline (Pro), and glycine (Gly), all of which were purchased from Aladdin Reagent Co., Ltd. (Shanghai, China). 1-Butyl-3-methylimidazolium bromide $\left(\left[\mathrm{C}_{4} \mathrm{mim}\right] \mathrm{Br}\right)$, 1-ethyl-3-methylimidazolium bromide $\left(\left[\mathrm{C}_{2} \mathrm{mim}\right] \mathrm{Br}\right)$, 1-hexyl-3-methylimidazolium bromide $\left(\left[\mathrm{C}_{6} \mathrm{mim}\right]\right.$ $\mathrm{Br}$ ), $N$-ethyl- $N$-methyl-pyrrolidinium bromide ([Pyr]Br), and $N$ ethyl- $N$-methyl-piperidinium bromide ([Pip]Br) ILs were obtained from the Shanghai Chengjie Chemical Co., Ltd. (Shanghai, China) with purities greater than 99\%. Tetraethylammonium hydroxide (25\% aqueous solution, $\left.\left[\mathrm{N}_{2,2,2,2}\right][\mathrm{OH}]\right)$, tetrabutylammonium hydroxide $(25 \%$ aqueous solution, $\left.\left[\mathrm{N}_{4,4,4,4}\right][\mathrm{OH}]\right)$, and choline hydroxide $(48-50 \%$ aqueous solution, $[\mathrm{Cho}][\mathrm{OH}])$, were bought from Chengdu Xiya Reagent Co., Ltd. (Chengdu, China).

Nine target microorganisms were used in this work, including three bacterial species (Escherichia coli (E. coli), Ralstonia solanacearum (R. solanacearum), Bacillus subtilis (B. subtilis)), four fungi (Ceriporiopsis subvermispora (C. subvermispora), Fomes lignosus (F. lignosus), Phanerochaete chrysosporium ( $P$. chrysosporium), Trametes sanguinea (T. sanguinea)), and two species of yeast (Saccharomyces cerevisiae (S. cerevisiae), and Scheffersomyces stipitis (S. stipitis)). These microorganisms were obtained from Institute of Bast Fiber Crops, Chinese Academy of Agricultural Sciences. Rice seeds (Oryza sativa L.) were purchased from Hunan Agricultural Abundant Seed Industry Co., Ltd. (Changsha, China). All other reagents used in this study were of analytical grade and used without further purification.

\section{Preparation of AAILS}

Nineteen AAILs were synthesized in this work. Twelve AAILs were prepared using the "two-step" method, ${ }^{37}$ including 1-butyl3-methyl-imidazolium L-prolinate $\left(\left[\mathrm{C}_{4} \mathrm{mim}\right][\right.$ Pro $\left.]\right)$, 1-butyl-3methyl-imidazolium L-valinate $\left(\left[\mathrm{C}_{4} \mathrm{mim}\right][\mathrm{Val}]\right), \quad$ 1-butyl-3methyl-imidazolium glycinate $\left(\left[\mathrm{C}_{4} \mathrm{mim}\right][\mathrm{Gly}]\right)$, 1-butyl-3methyl-imidazolium L-cysteinate $\left(\left[\mathrm{C}_{4} \mathrm{mim}\right][\mathrm{Cys}]\right)$, 1-butyl-3methyl-imidazolium L-histidinate $\left(\left[\mathrm{C}_{4} \mathrm{mim}\right][\mathrm{His}]\right)$, 1-butyl-3methyl-imidazolium L-phenylalaninate $\left(\left[\mathrm{C}_{4} \mathrm{mim}\right][\mathrm{Phe}]\right), 1$-butyl3-methyl-imidazolium L-aspartate $\left(\left[\mathrm{C}_{4} \mathrm{mim}\right][\right.$ Asp $\left.]\right)$, 1-ethyl-3methyl-imidazolium L-cysteinate $\left(\left[\mathrm{C}_{2} \mathrm{mim}\right][\mathrm{Cys}]\right)$, 1-hexyl-3-

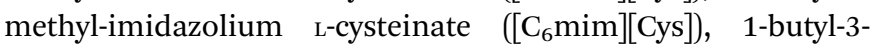
methyl-imidazolium L-cysteinate ([C $\left.\left.\mathrm{C}_{4} \mathrm{mim}\right][\mathrm{Cys}]\right), \quad N$-ethyl- $N$ methyl-pyrrolidinium L-cysteinate ([Pyr][Cys]), and $N$-ethyl- $N$ methyl-piperidinium L-cysteinate ([Pip][Cys]).

The other seven AAILs were prepared using the "one-step" method, ${ }^{31}$ including (2-hydroxyethyl)trimethylammonium glycinate ([Cho][Gly]), (2-hydroxyethyl)trimethylammonium L-prolinate ([Cho][Pro]), (2-hydroxyethyl)trimethylammonium Lhistidinate ([Cho][His]), (2-hydroxyethyl)trimethylammonium Lphenylalaninate ([Cho][Phe]), (2-hydroxyethyl)trimethylammonium L-aspartate ([Cho][Asp]), (2-hydroxyethyl)trimethylammonium L-cysteinate ([Cho][Cys]), tetraethylammonium Lcysteinate $\left(\left[\mathrm{N}_{2,2,2,2}\right][\mathrm{Cys}]\right)$, and tetrabutylammonium L-cysteinate $\left(\left[\mathrm{N}_{4,4,4,4}\right][\mathrm{Cys}]\right)$. All obtained AAILs were characterized via FT-IR spectroscopy and ${ }^{1} \mathrm{H}$ NMR, and these data are provided in the ESI. $\dagger$ 


\section{Bacteria toxicity test}

The toxic effect of each AAIL on three bacteria (E. coli, B. subtilis, and $R$. solanacearum) was assessed using the well diffusion method, as described by Ventura et al. ${ }^{38}$ Briefly, three target bacteria were cultured in nutrient broth at $37{ }^{\circ} \mathrm{C}$ for $12 \mathrm{~h}$, and then $10^{6}$ colony forming units (CFU) per $\mathrm{cm}^{3}$ of the suspension was diluted with nutrient broth. A $1 \mathrm{~mL}$ bacterial inoculum was then uniformly spread onto an agar surface. Four holes with $5.0 \mathrm{~mm}$ diameters were punched into the agar using a sterile borer under aseptic conditions, and $50 \mu \mathrm{L}$ AAILs solution at the desired concentration was placed into the four holes. The agar plates were incubated at $37{ }^{\circ} \mathrm{C}$ for $24 \mathrm{~h}$, after which the diameters of the growth inhibition zones were measured.

\section{Microbial toxicity assays}

The toxic effect of AAILs on microorganisms was evaluated using the tube dilution method. The tested microorganisms included three bacteria (E. coli, B. subtilis, and R. solanacearum), four fungi (C. subvermispora, F. lignosus, P. chrysosporium, and T. sanguinea), and two yeasts ( $S$. cerevisiae and $S$. stipitis). The bacteria were cultured in Mueller-Hinton broth medium at $37{ }^{\circ} \mathrm{C}$ for $24 \mathrm{~h}$, while the fungi and yeasts were cultured in Sabouraud agar medium at $28^{\circ} \mathrm{C}$ for $48 \mathrm{~h}$. A suspension of $10^{6}$

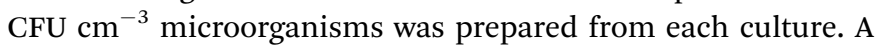
series of AAILs solutions (7.8-1000 mmol L ${ }^{-1}$ ) were then prepared with Mueller-Hinton broth (bacteria) or Sabouraud broth (fungi and yeasts), and sterilized via filtration $(0.45 \mu \mathrm{m}$ pore-diameter membrane) under sterile conditions. AAILs solution $(100 \mu \mathrm{L})$ and microorganism suspensions $(100 \mu \mathrm{L})$ were introduced into individual wells of a 96-well plate. A well with culture but no microorganism was used as negative control, while another well with a microorganism but no AAILs solution was used as a positive control. Microorganism growth was visually determined after incubation at $37^{\circ} \mathrm{C}$ for $24 \mathrm{~h}$ (bacteria) or at $28^{\circ} \mathrm{C}$ for $48 \mathrm{~h}$ (fungi and yeasts). The lowest concentration at which there was no visible growth (turbidity) was considered as the minimal inhibitory concentration (MIC). Samples of 20 $\mu \mathrm{L}$ from each well were spread onto an agar medium with inactivates $\left(0.3 \%\right.$ lecithin, $3 \%$ polysorbate- 80 , and $0.1 \% \mathrm{~L}^{-}$ cysteine), then incubated at $37{ }^{\circ} \mathrm{C}$ for $48 \mathrm{~h}$. The lowest concentration of the IL that killed $99.9 \%$ or more of the test microorganism was considered as the minimum biocidal concentration (MBC).

\section{Phytotoxicity tests}

The toxic effect of AAILs on rice seed germination was assessed using seeding emergence and seeding growth tests (OECD/OCED 208/2006). Prior to germination, rice seeds were sterilized in $2 \%$ $\mathrm{H}_{2} \mathrm{O}_{2}(\mathrm{v} / \mathrm{v})$ for $10 \mathrm{~min}$ and then washed three times with distilled water. For each AAIL solution at each concentration (200, 400, 600, 800 , and $1000 \mathrm{mg} \mathrm{kg}^{-1}$ ), seeds were soaked in $20 \mathrm{~mL}$ AAIL solution in the dark at $30 \pm 1{ }^{\circ} \mathrm{C}$ for $12 \mathrm{~h}$. Next, 20 seeds were placed in a Petri dish (diameter $90 \mathrm{~mm}$ ) on two pieces of filter paper moistened with $10 \mathrm{~mL}$ of the appropriate AAIL solution. One sample of rice seeds was treated with distilled water as a control, and all treatments were replicated three times. Rice seedlings were grown under controlled conditions at $28 \pm 1{ }^{\circ} \mathrm{C}$ with $80 \%$ humidity and a shift cycle of $14 \mathrm{~h}$ per day and $10 \mathrm{~h}$ per night. An equal amount of each AAIL solution was added to the appropriate plate every day to ensure sufficient moisture. After 10 days, the rice seeds were harvested, and their shoot height, root length, and fresh weight were measured, and the results were calculated by eqn (1)-(3). Shoot height, root length, and fresh weight of samples without treatment of AAILs were used as the control (CK). Higher concentration AAILs were not used to treat the seeds since the inhibition caused in some cases was strong enough to prevent any plant from growing.

$$
\begin{aligned}
\text { Shoot inhibition }(\%)= & {[\text { shoot height }(\mathrm{AAIL})-\text { shoot height }} \\
& (\mathrm{CK})] / \text { shoot height }(\mathrm{CK})
\end{aligned}
$$

Root inhibition $(\%)=[$ root length $(\mathrm{AAIL})-$ root length

$$
(\mathrm{CK})] / \text { root length }(\mathrm{CK})
$$

Fresh weight inhibition $(\%)=[$ fresh weight $($ AAIL $)-$ fresh weight

$$
(\mathrm{CK})] / \text { fresh weight }(\mathrm{CK})
$$

\section{Biodegradation test}

The biodegradability of the AAILs was assessed according to guideline 301D of the Organization for Economic Cooperation and Development (OECD). Briefly, a mineral medium was prepared consisting of $8.5 \mathrm{~g} \mathrm{~L}^{-1} \mathrm{KH}_{2} \mathrm{PO}_{4}, 21.75 \mathrm{~g} \mathrm{~L}^{-1} \mathrm{~K}_{2} \mathrm{HPO}_{4}$, $33.40 \mathrm{~g} \mathrm{~L}^{-1} \mathrm{Na}_{2} \mathrm{HPO}_{4} \cdot 2 \mathrm{H}_{2} \mathrm{O}, 0.5 \mathrm{~g} \mathrm{~L}^{-1} \mathrm{NH}_{4} \mathrm{Cl}, 27.5 \mathrm{~g} \mathrm{~L}^{-1} \mathrm{CaCl}_{2}$, $22.50 \mathrm{~g} \mathrm{~L}^{-1} \mathrm{MgSO}_{4} \cdot 7 \mathrm{H}_{2} \mathrm{O}$, and $0.25 \mathrm{~g} \mathrm{~L}^{-1} \mathrm{FeCl}_{3} \cdot 6 \mathrm{H}_{2} \mathrm{O}$. AAILs solution of $4 \mathrm{mg} \mathrm{L}^{-1}$ was prepared in the mineral medium and incubated with aerated water from Taozi Lake (Changsha, China). A control with inoculums but without AAIL was used as a blank, and sodium benzoate was used as a reference substance. These test solutions were placed in closed bottles and were kept in the darkness at $25 \pm 1{ }^{\circ} \mathrm{C}$ for 28 days. The biological oxygen demand (BOD) of the samples was determined using a dissolved oxygen meter (Firesting $\mathrm{O}_{2}$, Pyroscience Germany) every 7 days. AAIL biodegradation rates were calculated by dividing the BOD by the theoretical chemical oxygen demand (TCOD).

\section{Statistical analysis}

The proton nuclear magnetic resonance $\left({ }^{1} \mathrm{H}\right.$ NMR) data of AAIL samples were analyzed using MestReNova LITE 9.0.1, and Fourier transform infrared spectroscopy (FT-IR) data were analyzed by OriginLab 8.0 (OriginLab Corporation, American). Toxic and biodegradable data were analyzed using the graphics program GraphPad Prism v5.0b (GraphPad Software Inc.). All data are presented as the mean of three independent experiments with error values expressed as the standard error of the mean (SEM).

\section{Results and discussion}

\section{Antibacterial activity}

The well diffusion method is widely used to screen chemicals for toxicity due to its simplicity, where the toxicity of a chemical is determined by the diameter of the growth inhibition zones. ${ }^{39}$ 
In this study, the effects of the AAILs were evaluated via well diffusion assays with target bacteria. Tables S1-3† show the results of all tested AAILs against the bacteria B. subtilis, $R$. solanacearum, and E. coli. The growth inhibition halos $(\mathrm{cm})$ for the highest AAIL concentration $\left(1.00 \mathrm{~mol} \mathrm{~L}^{-1}\right)$ tested against the three target bacteria are shown in Fig. 2. Most AAILs at the lowest concentration $\left(0.0625 \mathrm{~mol} \mathrm{~L}^{-1}\right)$ were found to be nontoxic (no inhibition zone) against the three target bacteria, while some AAILs demonstrated low toxicity towards the target bacteria even at the highest concentration $\left(1.00 \mathrm{~mol} \mathrm{~L}^{-1}\right)$. For example, the inhibition zones of B. subtilis and E. coli induced by the highest concentration $\left(1.00 \mathrm{~mol} \mathrm{~L}^{-1}\right)$ of [Cho][Asp] solution were 0.73 and $0.20 \mathrm{~cm}$, respectively (Fig. 2d). However, most AAILs were toxic against target bacteria at high concentrations, and their toxicity increased with increased AAIL concentration. For example, the growth inhibition halo of $R$. solanacearum induced by $\left[\mathrm{C}_{4} \mathrm{mim}\right][\mathrm{Pro}]$ at different concentrations $\left(0.0625,0.125,0.25,0.50,1.00 \mathrm{~mol} \mathrm{~L}^{-1}\right)$ were $0.00,0.60$, $0.70,0.80$, and $1.07 \pm 0.06 \mathrm{~cm}$, respectively (Table S2 $\dagger$ ). Moreover, the results showed that the AAILs' toxic effect on target bacteria is different, and the toxicity of AAILs is greatly related to the kinds of cation core, alkyl chain length and anions. ${ }^{38}$

The effect of AAILs containing cations with alkyl imidazoliums (carbon atom $=2,4$, or 6) or alkyl ammonia (carbon atom $=2$ or 4 ) against the three bacteria were also evaluated in this study (Fig. 2a). The diameters of the inhibition zones of $B$. subtilis exposed to $\left[\mathrm{C}_{2} \mathrm{mim}\right][\mathrm{Cys}],\left[\mathrm{C}_{4} \mathrm{mim}\right][\mathrm{Cys}]$, and $\left[\mathrm{C}_{6} \mathrm{mim}\right]$ [Cys] at $0.025 \mathrm{~mol} \mathrm{~L}^{-1}$ were $0.00,0.52 \pm 0.02$, and $0.83 \pm$ $0.06 \mathrm{~cm}$, respectively (Table S1†). Additionally, the diameters of the inhibition zone of B. subtilis treated with $\left[\mathrm{N}_{2,2,2,2}\right][\mathrm{Cys}]$ and $\left[\mathrm{N}_{4,4,4,4}\right][$ Cys $]$ solution $\left(0.025 \mathrm{~mol} \mathrm{~L}^{-1}\right)$ were 0.00 and $0.93 \pm$
$0.06 \mathrm{~cm}$, respectively (Table S1 $\dagger$ ). The toxic effect of these AAILs on other target bacteria was comparable to their effect on $B$. subtilis. This phenomenon is known as "chain length effect" (toxicity increases with an increase in alkyl chain length), ${ }^{40}$ and occurs because cations with long alkyl chain are more hydrophobic and more easily pass through the membranes of microorganisms than short alkyl chains.$^{41}$ Thus, AAILs with longer alkyl chain are more destructive on microorganisms. This result shows that alkyl chain length plays an important role in AAILs' antibacterial activity. ${ }^{38}$

As shown in Fig. $2 \mathrm{~b}$, the diameter of the inhibition halo of $B$. subtilis treated with AAILs containing cations with different conventional head groups and $\mathrm{L}$-cysteine anions under the same conditions are different. For example, the halo diameters of $B$. subtilis induced by $\left[\mathrm{C}_{4} \mathrm{mim}\right][\mathrm{Cys}]$, [Cho][Cys], [Pyr][Cys], [Pip] [Cys], and $\left[\mathrm{N}_{4,4,4,4}\right][\mathrm{Cys}]$ solution (all $1.00 \mathrm{~mol} \mathrm{~L}^{-1}$ ) were $0.93 \pm$ $0.04,0.00,0.90 \pm 0.10,0.60 \pm 0.10$, and $1.33 \pm 0.06 \mathrm{~cm}$, respectively (Table $\mathrm{S} 1 \dagger$ ). The sequence of these head group from least to most toxic was [Cho $]^{+}<[\mathrm{Pip}]^{+}<[\mathrm{Pyr}]^{+}<\left[\mathrm{C}_{4} \text { mim }\right]^{+}<$ $\left[\mathrm{N}_{4,4,4,4}\right]^{+}$, showing that the toxic effect of choline amino acidbased ionic liquids was lower than that of the other AAILs. ${ }^{42}$ These results were in accord with that reported by Gouveia, they prepared 14 AAILs with different cations (imidazolium, pyridinium and cholinium) and anions (arginine, glutamine, glutamic acid and cystine) and studied their toxicity to bacteria and cells. $^{37}$ However, head group with cyclic structure is more destructive on target bacteria, and because cyclic structure is too stable to be damaged. In addition, ILs containing $\left[\mathrm{N}_{4,4,4,4}\right]^{+}$ have a good antimicrobial activity as well. These results suggest that the head group makes a major contribution to AAIL toxicity. (a)

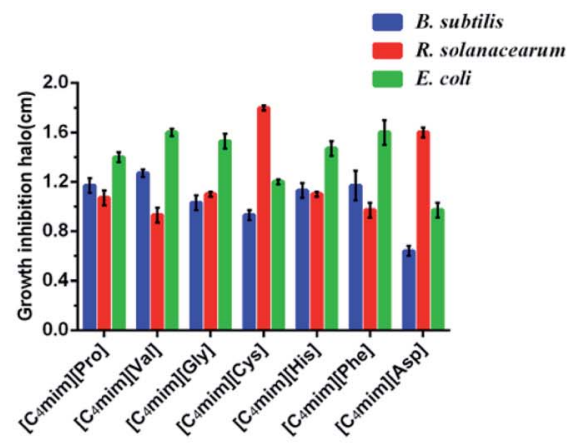

(c)

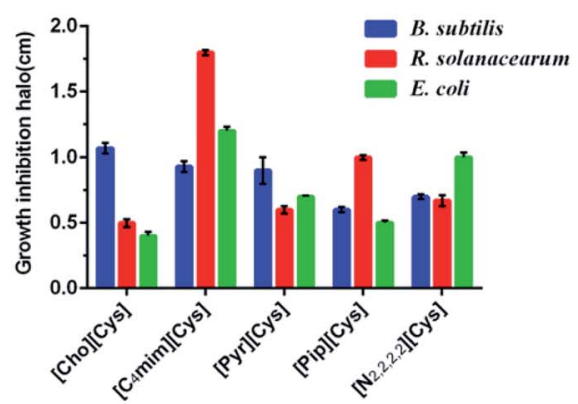

(b)

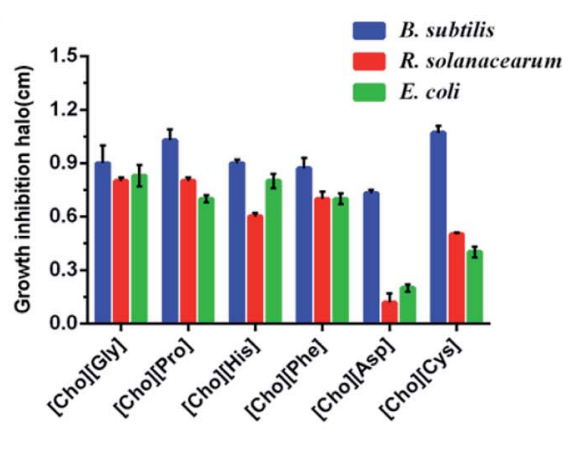

(d)

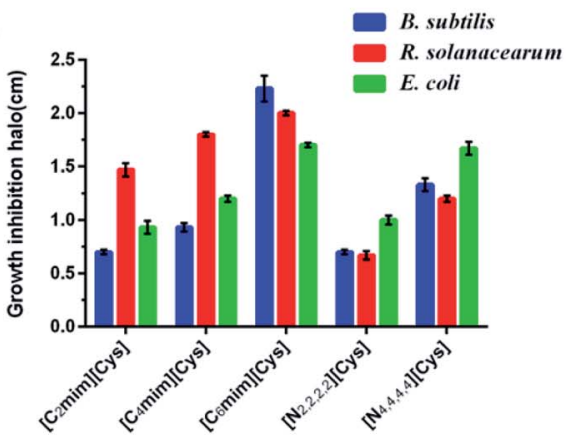

Fig. 2 The growth inhibition halo $(\mathrm{cm})$ for the highest tested concentration of AAILs $\left(1.00 \mathrm{~mol} \mathrm{~L} \mathrm{~L}^{-1}\right)$ against three target bacteria $B$. subtilis, $R$. solanacearum, and E. coli. 
The diameter of the inhibition zone of $R$. solanacearum exposed to [Cho][Asp] or [ $\left.\mathrm{C}_{4} \mathrm{mim}\right][$ Asp] solution was zero even at a high concentration $\left(0.50 \mathrm{~mol} \mathrm{~L}^{-1}\right)$ (Table $\left.\mathrm{S} 2 \dagger\right)$. Moreover, the [Cho][Asp] concentration at $1.00 \mathrm{~mol} \mathrm{~L}^{-1}$ was also less toxic against B. subtilis and E. coli (Fig. 2d). However, the toxicities of other AAILs with the same cation and different anions were distinctly different because toxicity is also related to physicochemical properties of the anion, such as hydrophilicity or hydrophobicity. To the best of our knowledge, $\left[\mathrm{C}_{4} \mathrm{mim}\right][$ Asp] possesses one hydrophilic carboxyl groups, which can't easily pass through the membrane of microorganisms. ${ }^{43}$ For this reason, the effect of $\left[\mathrm{C}_{4} \mathrm{mim}\right][\mathrm{Asp}]$ on target bacteria was lower than that of other AAILs with a $\left[\mathrm{C}_{4} \mathrm{mim}\right]$ cation. In addition, the stability of anions is also an important factor affecting ILs toxicity, for example, the toxic effect of AAILs with phenylalaninate anions on target bacteria is stronger than that of other anions. ${ }^{12}$ These results show that the anions species also play a role in the toxicity of AAILs.

The diameters of the inhibition zones of $R$. solanacearum, $E$. coli, and B. subtilis treated with the highest concentration $\left(1.00 \mathrm{~mol} \mathrm{~L}^{-1}\right)$ of [Cho][Pro] solution were $0.80,0.70$, and $1.03 \pm$ $0.06 \mathrm{~cm}$, respectively (Fig. 2d). Gram-positive bacteria possess thicker and more hydrophobic cell walls, ${ }^{44}$ and a much higher peptidoglycan content ( $\sim 90 \%)$. The cell walls of Gram-negative bacteria are chemically more complex, which have an additional outer membrane mostly composed of lipopolysaccharides. ${ }^{45}$ The latter is often related to the higher resistance of Gram-negative bacteria to biocides. ${ }^{46}$ The Gram-negative bacteria had higher tolerances than the Gram-positive bacteria, which can be attributed to the fact that Gram-negative bacteria possess a second cell membrane which acts as an additional barrier. These results agree well with the findings reported by Mester et al. ${ }^{43}$

\section{Antimicrobial activity}

Although the well diffusion method mentioned above can easily verify if the AAILs have toxicity to microorganisms, it can't quantificationally assess the toxicity. ${ }^{39}$ Therefore, antimicrobial activity of the nineteen AAILs were also estimated using the tube dilution method, this time with nine microorganisms: three bacteria (E. coli, B. subtilis, and R. solanacearum), four fungi ( $C$. subvermispora, F. lignosus, P. chrysosporium, and T. sanguinea), and two yeasts ( $S$. cerevisiae and $S$. stipitis). The tube dilution test is usually used to determine the minimum inhibitory concentration (MIC) and the minimum bactericidal/fungicidal concentration (MBC/MFC), which are two essential parameters in antimicrobial susceptibility testing. The MIC and MBC values (in $\mathrm{mM}$ ) for the AAILs are shown in Table S4. $\dagger$ According to the reports by Gathergood, the toxicity of ILs was divided into three levels, and which was indicated as three colors, green, amber, and red. The green color represents the MIC/MBC value $>2 \mathrm{mM}$, the amber color represents the MIC/MBC value between 0.25 and $2.0 \mathrm{mM}$, and the red color represents the MIC/MBC value < $0.25 \mathrm{mM} .{ }^{47}$ Fortunately, all the tested AAILs in this study had the $\mathrm{MIC} / \mathrm{MBC}$ value $>2 \mathrm{mM}$, which indicated AAILs were much safer from this aspect. Even so, the AAILs with different structures had different inhibiting effect to the tested microorganisms. It was found that the AAILs that incorporated the choline cation showed lower toxicity than other tested compounds towards target microorganisms. For instance, the MIC/MBC value of [Cho][Asp] toward $R$. solanacearum, $C$. subvermispora, and $F$. lignosus was highest (>1000 mM) among all tested compounds, which might be attributed to the nontoxic choline as well as the presence of carbonyl acids groups. This was accordance with the studies by $\mathrm{Hou}$, the MIC/MBC value of [Cho][Asp], [Cho][Glu] and [Cho][Aco] toward Escherichia coli, Staphylococcus aureus, Salmonella enteritidis, and Listeria monocytogenes was also highest among $21 \mathrm{ILs}^{36}$ In addition, since the cell membrane of the microorganisms is hydrophobic, the tested hydrophilic compounds could not pass through it or disrupt it easily, allowing the microorganisms to tolerate a higher concentration of [Cho][Asp]. Similarly, [ $\left.\mathrm{C}_{4} \mathrm{mim}\right]$ [Asp] had a lower toxicity than the other AAILs containing $\left[\mathrm{C}_{4} \mathrm{mim}\right]^{+}$, probably due to the presence of the hydrophilic $\mathrm{L}^{-}$ aspartic acid. In other words, differences in the toxicity of AAILs could be attributed to the structures of the anions. It can be seen in Table $\mathrm{S} 4 \uparrow$ that the target microorganisms were more sensitive to $\left[\mathrm{N}_{4,4,4,4}\right][\mathrm{Cys}]$ than $\left[\mathrm{N}_{2,2,2,2}\right][\mathrm{Cys}]$, which is attributable to the increase in lipophilicity in the cations. ${ }^{\mathbf{4 1}}$

Similarly, the toxicity of imidazolium-based AAILs increased with the elongation of side chain in the alkylimidazolium cation. For instance, the $\mathrm{MBC}$ values of $\left[\mathrm{C}_{2} \mathrm{mim}\right][\mathrm{Cys}],\left[\mathrm{C}_{4} \mathrm{mim}\right]$ [Cys], and $\left[\mathrm{C}_{6} \mathrm{mim}\right][\mathrm{Cys}]$ toward $S$. cerevisiae were 125, 62.5, and $31.3 \mathrm{mM}$, respectively. This phenomenon is described as "alkyl chain length effect," as mentioned in section Antibacterial activity. Although $\left[\mathrm{C}_{4} \mathrm{mim}\right][\mathrm{Cys}]$ and $\left[\mathrm{C}_{6} \mathrm{mim}\right][\mathrm{Cys}]$ have different numbers of carbons in their cations, the $\mathrm{MBC}$ values of them for $R$. solanacearum were the same $\left(125 \mathrm{mmol} \mathrm{L}^{-1}\right)$. This behavior is described as a "cut off effect" where there is a maximal effect above which an increase in alkyl chain length does not produce an increase in toxicity. ${ }^{\mathbf{4 0 , 4 8}}$

Differences in the antimicrobial activities of AAILs containing an L-cystine anion might be attributable to differences in the head group. For instance, the presence of a heterocyclic imidazole group in $\left[\mathrm{C}_{4} \mathrm{mim}\right][\mathrm{Cys}]$ lead to an increased toxic effect on target microorganisms compared with AAILs without a heterocyclic ring such as [Cho][AA]. Similar behavior was also observed in the toxicity values of [Pyr][Cys] and [Pip][Cys], due to the presence or absence of a heterocyclic ring in the cation. ${ }^{49}$

Moreover, specific AAILs showed different toxic effects against different target microorganisms. For example, the MBC values for [Cho][Phe] when targeting B. subtilis, R. solanacearum, and E. coli were $125,500,250 \mathrm{mmol} \mathrm{L}^{-1}$, respectively. The target $B$. subtilis is a Gram-positive bacterium, which has a thick and multilayered cell wall made of peptidoglycan surrounding the cytoplasmic membrane, while Gram-negative bacteria have a cell wall made up of a cytoplasmic membrane, peptidoglycan layer, and an external cytoplasmic membrane. ${ }^{50}$ The presence of a more structurally complex cell wall gave the Gram-negative bacteria a greater tolerance to AAILs than the Gram-positive bacteria. Similarly, the $\mathrm{MBC}$ values of $\left[\mathrm{C}_{4} \mathrm{mim}\right][\mathrm{Cys}]$ when targeting the two yeasts were lower than those when targeting bacteria or fungi, indicating that yeasts were the microorganism most sensitive type to AAIL toxicity. While yeasts also possess a protective capsule, this capsule must be easily destroyed by AAILs. ${ }^{51}$ 


\section{Phytotoxicity tests}

The toxicity of the investigated AAILs at various concentrations against rice seed germination is shown in Tables S5-7. $\dagger$ The results of these tests showed that AAILs at low concentrations possessed a low toxic effect on seed germination. For instance, root inhibition after exposure to $200 \mathrm{mg} \mathrm{kg}^{-1}$ [ $\left.\mathrm{C}_{4} \mathrm{mim}\right][\mathrm{Phe}]$ was the lowest $(-3.91 \%)$ among all tested concentrations. As the AAIL concentrations increased, the adverse effect of AAILs on seed growth significantly increased. However, some AAILs promoted the growth of rice seeds under both low and high test concentrations. For example, the root length of rice treated with $200 \mathrm{mg} \mathrm{kg}^{-1}$ of [Cho][Asp] for 10 days was eight times greater than that of rice without treatment. This pattern held true even after exposure of rice seeds to the highest concentration of AAIL (1000 $\mathrm{mg} \mathrm{kg}^{-1}$ ). And thus, [Cho][Asp] can be expected to be used as the growth accelerator for rice. The mechanism of these results is thought to be due to the attractive force between the cations and anions that make up the ILs. This attraction is stronger at high concentrations and weakens at low concentrations. $^{52}$ In this case, the [Cho][AA] was ionized to cholinium cations and amino acid anions, which can promote the plant growth. Similar results have been reported for wheat seedlings, ${ }^{53}$ exposure to the low concentrations of the IL 1-butyl-3methylimidazolium tetrafluoroborate promoted seedling growth.

The difference in the effects of [Cho][AA] on seed germination might be attributed to the structures of anions, as can be seen in the data presented in Table S5.† For instance, [Cho][Asp] had a positive impact on the growth of rice seeds at all tested concentrations, which suggests that maybe the introduction of a carbonyl acid group significantly reduced the toxic effect of AAILs on rice.

In previous reports cations have been shown to play an important role in the toxicity of ILs. ${ }^{54-56}$ Therefore, in this study, AAILs composed of various cations combined with an L-cysteine anion were examined to determine their toxicity in rice. It can be seen in Table $\mathrm{S} 5 \uparrow$ that the adverse effect of $\left[\mathrm{C}_{4} \mathrm{mim}\right][\mathrm{Cys}]$ on root growth was stronger than that of [Cho][Cys], which indicates that the presence of a heterocyclic ring increased phytotoxicity. Similarly, [Pyr][Cys] had a greater toxic effect on seed growth $(-25.77 \%$ shoot inhibition) was found (Table S6†). For example, the root inhibition (\%) for [Cho][Cys], [C $\left.\mathrm{C}_{4} \mathrm{mim}\right][\mathrm{Cys}]$, [Pyr][Cys], [Pip][Cys], and $\left[\mathrm{N}_{4,4,4,4}\right][\mathrm{Cys}]$ was $-100 \pm 4.58 \%, 2.07$ $\pm 0.03 \%,-40.99 \pm 1.21 \%,-9.09 \pm 0.02 \%$, and $-100 \pm 0.26 \%$, respectively at $1000 \mathrm{mg} \mathrm{kg}^{-1}$ IL concentration. So a rough order of toxicity was obtained, that was $[\mathrm{Cho}]^{+}<[\mathrm{Pip}]^{+}<[\mathrm{Pyr}]^{+}<$ $\left[\mathrm{C}_{\mathrm{n}} \mathrm{mim}\right]^{+} \approx\left[\mathrm{N}_{n, n, n, n}\right]^{+}$. This order is also identical with the result in antimicrobial activity mentioned above and other reports. $^{12}$

In contrast, the observed effect of the AAILs on root length, shoot length, and fresh weight of rice showed that the introduction of an alkyl side chain in cations affected AAIL toxicity. Specifically, shoot inhibitions of $\left[\mathrm{C}_{2} \mathrm{mim}\right][\mathrm{Cys}],\left[\mathrm{C}_{4} \mathrm{mim}\right][\mathrm{Cys}]$, and $\left[\mathrm{C}_{6} \mathrm{mim}\right][\mathrm{Cys}]$ were $-4.96 \%,-22.71 \%$, and $97.47 \%$, respectively (Table $\mathrm{S} 6 \dagger$ ). As the data show, the toxic effect of AAILs on rice increased with the elongation of the alkyl chain, which may be attributed to the increase of lipophilicity as the alkyl chain increased. ${ }^{\mathbf{1 4}}$ Compounds with more pronounced lipophilic characters can interact more easily with the hydrophobic domains of membrane proteins and with the phospholipid bilayers that make up the cell membrane. This interaction may disrupt physiological function in the cell membrane and increase AAIL toxicity. ${ }^{57}$ Similarly, $\left[\mathrm{N}_{4,4,4,4}\right][\mathrm{Cys}]$ showed greater toxicity than $\left[\mathrm{N}_{2,2,2,2}\right][\mathrm{Cys}]$ (Table $\mathrm{S} 6 \dagger$ ). This phenomenon has also been reported in an assessment of IL phytotoxicity toward rice seedlings using imidazolium chloride. $^{58}$

The effect of anions on ILs toxicity can't be neglected either. It can be seen in Tables S5-7† that the IL $\left[\mathrm{C}_{4} \mathrm{mim}\right][\mathrm{Br}]$ generally had larger toxicity than the $\left[\mathrm{C}_{4} \mathrm{mim}\right][\mathrm{AA}]$. For example, the fresh weight inhibition (\%) for $\left[\mathrm{C}_{4} \mathrm{mim}\right][\mathrm{Pro}],\left[\mathrm{C}_{4} \mathrm{mim}\right][\mathrm{Val}],\left[\mathrm{C}_{4} \mathrm{mim}\right]$ $[\mathrm{Gly}],\left[\mathrm{C}_{4} \mathrm{mim}\right][\mathrm{Cys}],\left[\mathrm{C}_{4} \mathrm{mim}\right][\mathrm{His}],\left[\mathrm{C}_{4} \mathrm{mim}\right][\mathrm{Phe}],\left[\mathrm{C}_{4} \mathrm{mim}\right][\mathrm{Asp}]$, and $\left[\mathrm{C}_{4} \mathrm{mim}\right][\mathrm{Br}]$ was $-17.24 \pm 0.06 \%,-20.69 \pm 0.26 \%,-29.31$ $\pm 0.37 \%,-17.24 \pm 0.29 \%,-17.24 \pm 0.15 \%,-20.69 \pm 0.03 \%$, $-6.90 \pm 0.01 \%$, and $31.03 \pm 0.02 \%$, respectively (Table S7 $\dagger$ ). Therefore, the introduction of amino acids in anions helped reduce the toxicity the toxicity of ILs. Moreover, it can be seen in Table S5 $\uparrow$ that the toxicity of [Cho][AA] followed the order of $[$ Cho $][$ Gly $]>[$ Cho $][$ Asp $]>[$ Cho $][$ Phe $]>[$ Cho $][$ Pro $]>[$ Cho $][$ Cys $] \approx$ [Cho][His]. These results also approved that the anions can also affect the toxicity of AAILs. This behavior contradicts previous studies which reported that anions had only a small impact in reducing IL toxicity. The difference might be attributable to the introduction of choline. ${ }^{59}$

\section{Biodegradability}

In contrast to chemical degradation which requires the assistance of an oxidant for catalysis, biodegradation is the breakdown of chemical compounds by microbes. ${ }^{60}$ In general, the biodegradation test methods are considered to be valid if the reference compound of $>60 \%$ is biodegraded within 14 days. In this study, the biodegradability of sodium benzoate was measured as $61.2 \%$ in 14 days, which proved the validity of this test method. As can be seen in Fig. 3, [Cho][AA] possessed good biodegradability (biodegradation $>60 \%$ ) in all cases except for [Cho][Phe], which allows them to be classified as "readily biodegradable" according to OECD standards. According to the reports by Gathergood, the degradation rate was divided into three levels, degradation rate $>60 \%$ represented by green color, degradation rate between $0-59 \%$ represented by amber color, and degradation rate $<20 \%$ represented by red color. ${ }^{47}$ [Cho] [AA] was prepared from renewable biomaterials, which are unstable in the environment and are easily decomposed by microbes. ${ }^{36}$ Moreover, [Cho][AA] is an attractive compound for use in industry due to its low microbial toxicity, as described in section Antibacterial activity and Antimicrobial activity. Compared with the results reported by $\mathrm{Hou},{ }^{36}$ the biodegradability of AAILs in this study was relatively lower, the reason can be that the inoculum was lake water and the OECD 301D method was chosen as the test method according to guideline 301D of the Organization for Economic Cooperation and Development (OECD). Other tested AAILs, however, showed 

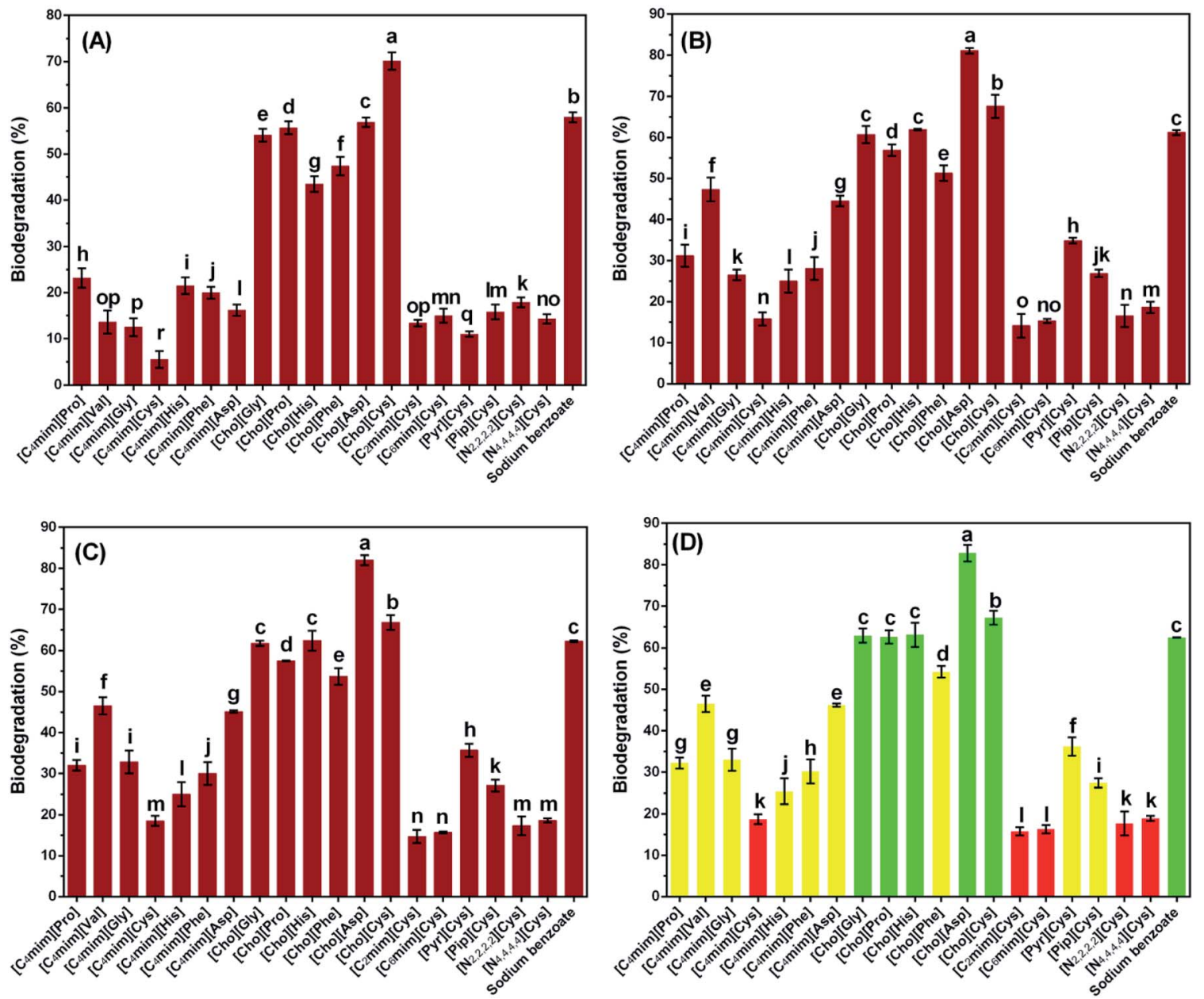

Fig. 3 Biodegradation of AAILs determined by the closed bottle tests (A) 7 days; (B) 14 days; (C) 21 days; and (D) 28 days. Green: $60 \%$, readily biodegradable; amber: 20-59\%, potential biodegradability; red: 0-19\%, poor biodegradability.

poor degradability, as in the case of $\left[\mathrm{C}_{4} \mathrm{mim}\right][\mathrm{Cys}]$, who had the lowest biodegradability $(15.8 \pm 1.0 \%, 28$ days $)$ among all tested compounds.

The biodegradation of AAILs consisting of a 1-butyl-3methylimidazolium cation and assorted amino acid anions was diverse after 28 days, which can be attributed to the differences in anion structures. For instance, the biodegradability of $\left[\mathrm{C}_{4} \mathrm{mim}\right][\mathrm{Cys}]$ and $\left[\mathrm{C}_{4} \mathrm{mim}\right][$ Asp $]$ were $18.7 \pm 1.2 \%$ and $46.2 \pm 0.4 \%$, respectively. $\left[\mathrm{C}_{4} \mathrm{mim}\right][$ Asp] contains both amide and carboxylic acid groups and showed a high degree of biodegradation. This result agrees with Boethling's rule of thumb, which states that the presence of hydrolyzable bonds and carboxylate groups such as amides generally improved the biodegradability. ${ }^{61,62}$ However, the presence of carboxyl group amino acids in $\left[\mathrm{C}_{4} \mathrm{mim}\right][\mathrm{Asp}]$ led to slower breakdown by inoculum microorganisms and a low degree of aerobic biodegradability. Similarly, the AAILs consisting of anions that contain heterocyclic imidazole groups or aromatic carbon ring structures, such as [His] and [Phe], were less susceptible to microbial break down because of their high toxicity toward microorganisms. For instance, the biodegradations of $\left[\mathrm{C}_{4} \mathrm{mim}\right][\mathrm{His}]$ and $\left[\mathrm{C}_{4} \mathrm{mim}\right][\mathrm{Phe}]$ were $25.4 \pm 3.1 \%$ and $30.2 \pm 2.9 \%$, respectively.
Differences in the biodegradability of various AAILs incorporating a [Cys] anion with different head group cations, such as cholinium, imidazolium, piperidinium, quaternary ammonium, and pyrrolidinium, were also examined. AAILs that contained imidazolium showed lower aerobic biodegradability ([C $\left.\mathrm{C}_{4} \mathrm{mim}\right][\mathrm{Cys}], 18.7 \pm 1.2 \%$ ) than AAILs that contained choline ([Cho][Cys], $67.2 \pm 1.7 \%$ ) (Fig. 3), which could be attributed to the presence of the stable hetero cyclic imidazole group. ${ }^{14}$ Similarly, Gathergood et al. found that imidazolium ILs were classified as red (poor biodegradability) using the $\mathrm{CO}_{2}$ headspace test (ISO 14593), and they suggested that imidazolium salts containing a heterocyclic ring were difficult for microorganisms to degrade. ${ }^{60}$ The relatively low biodegradability of [Pyr] [Cys] and [Pip][Cys] might therefore be attributed to the presence of a N-containing heterocyclic group, which may be more resistant to microbe attack. Additionally, the microbial toxicity of AAILs containing quaternary ammonium were high, as described in section Antimicrobial activity, which should decrease inoculum density in closed bottle, leading to the poor biodegradation of $\left[\mathrm{N}_{2,2,2,2}\right][\mathrm{Cys}](17.7 \pm 2.9 \%){ }^{14}$

The biodegradability of AAILs improved slightly as the side chain length of cations increased. For instance, $\left[\mathrm{N}_{4,4,4,4}\right][\mathrm{Cys}]$ possesses a long alkyl chain and showed higher aerobic 
biodegradability than $\left[\mathrm{N}_{2,2,2,2}\right][\mathrm{Cys}]$. Similarly, $\left[\mathrm{C}_{4} \mathrm{mim}\right][\mathrm{Cys}]$ is more susceptible to breakdown by aerobic microorganisms than $\left[\mathrm{C}_{2} \mathrm{mim}\right][\mathrm{Cys}]$. However, the biodegradability of $\left[\mathrm{C}_{6} \mathrm{mim}\right]$ [Cys] was lowest among $\left[\mathrm{C}_{2} \mathrm{mim}\right][\mathrm{Cys}],\left[\mathrm{C}_{4} \mathrm{mim}\right][\mathrm{Cys}]$, and $\left[\mathrm{C}_{6} \mathrm{mim}\right][\mathrm{Cys}]$, which is similar to the "cut off effect". Moreover, the similar results can be found in $\left[\mathrm{N}_{n, n, n, n}\right][\mathrm{AA}](n=2,4)$, the $\left[\mathrm{N}_{4,4,4,4}\right][\mathrm{Cys}]$ had lower toxicity than $\left[\mathrm{N}_{2,2,2,2}\right][\mathrm{Cys}] \cdot{ }^{37}$ It can also been concluded in Fig. 3 that the biodegradability of AAILs with cysteine anion followed the order: $[\mathrm{Cho}]^{+}>[\mathrm{Pyr}]^{+}>[\mathrm{Pip}]^{+}>$ $\left[\mathrm{N}_{4,4,4,4}\right]^{+} \approx\left[\mathrm{C}_{4} \mathrm{mim}\right]^{+}>\left[\mathrm{N}_{2,2,2,2}\right]^{+}>\left[\mathrm{C}_{6} \mathrm{mim}\right]^{+}>\left[\mathrm{C}_{2} \mathrm{mim}\right]^{+}$. This order is contrary to the toxicity, which indicated that the larger toxicity, the lower biodegradability. The results also approved that the cations of AAILs can affect the biodegradability.

As to the anions of amide acids, it can be divided into aliphatic and cyclic amide acids. For example, the biodegradability of $\left[\mathrm{C}_{4} \mathrm{mim}\right][\mathrm{Gly}],\left[\mathrm{C}_{4} \mathrm{mim}\right][\mathrm{Val}],\left[\mathrm{C}_{4} \mathrm{mim}\right][\mathrm{Asp}],\left[\mathrm{C}_{4} \mathrm{mim}\right]$ [Cys] was $33.0 \pm 2.7 \%, 46.5 \pm 2.0 \%, 18.7 \pm 1.2 \%$, and $46.2 \pm$ $0.4 \%$, respectively, which generally had lower toxicity than the AAILs with ring in anions except $\left[\mathrm{C}_{4} \mathrm{mim}\right][\mathrm{Asp}]$, while the biodegradability of $\left[\mathrm{C}_{4} \mathrm{mim}\right][$ Phe $]$ was $30.2 \pm 2.9 \%$. The similar results can be found in [Cho][AA]. For example, the biodegradability of [Cho][Phe] was $54.2 \pm 1.4 \%$, which was lowest among the $[\mathrm{Cho}][\mathrm{AA}] .^{36}$

\section{Conclusions}

In this study, the antimicrobial activity, phytotoxicity, and biodegradability of 19 AAILs with different cations and anions were evaluated. The main factors affecting the toxicity and biodegradability of AAILs, including the type of cations (head groups and side chain) and anions (hydrophobic, hydrophilic or stability), were examined. The results showed that AAIL toxicity was mainly depended on the structures of the cations and anions. Toxicity increased with the elongation of alkyl chain length and decreased with the introduction of hydrophilic groups. The presence of a long alkyl chain in the cation and of hydrophilic groups in the anions can improve AAILs' biodegradability. Although the introduction of amino acids as anions can improve toxicity and biodegradation of AAILs, the (eco) toxicity and (bio)degradation of some AAILs can't be ignored neither. The results showed that not all AAILs' microbial toxicity was expected to be low and that some AAILs have high toxicity toward target microorganisms. Moreover, the phytotoxic effect of AAILs on Oryza sativa L. further demonstrated that the effect of AAILs on plants should not be ignored. Some AAILs, like [Cho][Asp] can be expected to be used as growth accelerator. The biodegradability tests showed that the majority AAILs had dissatisfactory biodegradability $(\leq 60 \%)$. Therefore, it can be concluded that since not all AAILs have low toxicity and good biodegradation, it is necessary to assess the effect of AAILs on the environment and human health before their use in applications for the mass-market.

\section{Conflicts of interest}

The authors declare no conflicts of interest.

\section{Acknowledgements}

This work was financially supported by the National Natural Science Foundation of China (No. 21878326 and 21406262), the Hunan Provincial Natural Science Foundation (No. 2019JJ50713) and the Training Program for Excellent Young Innovators of Changsha (No. kq1802018).

\section{References}

1 R. D. Rogers and K. R. Seddon, Science, 2003, 302, 792-793.

2 M. V. Fedorov and A. A. Kornyshev, Chem. Rev., 2014, 114, 2978-3036.

3 M. Smiglak, J. M. Pringle, X. Lu, L. Han, S. Zhang, H. Gao, D. R. MacFarlane and R. D. Rogers, Chem. Commun., 2014, 50, 9228-9250.

4 M. Watanabe, M. L. Thomas, S. Zhang, K. Ueno, T. Yasuda and K. Dokko, Chem. Rev., 2017, 117, 7190-7239.

5 H.-P. Steinruck and P. Wasserscheid, Catal. Lett., 2015, 145, 380-397.

6 M. Armand, F. Endres, D. R. MacFarlane, H. Ohno and B. Scrosati, Nat. Mater., 2009, 8, 621.

7 S. P. M. Ventura, F. A. e Silva, M. V. Quental, D. Mondal, M. G. Freire and J. A. P. Coutinho, Chem. Rev., 2017, 117, 6984-7052.

8 B. Lv, Y. Shi, C. Sun, N. Liu, W. Li and S. Li, Chem. Eng. J., 2015, 270, 372-377.

9 C. Wang, G. Cui, X. Luo, Y. Xu, H. Li and S. Dai, J. Am. Chem. Soc., 2011, 133, 11916-11919.

10 A. George, A. Brandt, K. Tran, S. M. S. N. S. Zahari, D. KleinMarcuschamer, N. Sun, N. Sathitsuksanoh, J. Shi, V. Stavila, R. Parthasarathi, S. Singh, B. M. Holmes, T. Welton, B. A. Simmons and J. P. Hallett, Green Chem., 2015, 17, 1728-1734.

11 K. S. Egorova, E. G. Gordeev and V. P. Ananikov, Chem. Rev., 2017, 117, 7132-7189.

12 M. Amde, J.-F. Liu and L. Pang, Environ. Sci. Technol., 2015, 49, 12611-12627.

13 A. Jordan, A. Haib, M. Spulak, Y. Karpichev, K. Kummerer and N. Gathergood, Green Chem., 2016, 18, 4374-4392.

14 S. P. F. Costa, A. M. O. Azevedo, P. C. A. G. Pinto and M. L. M. F. S. Saraiva, ChemSusChem, 2017, 10, 2321-2347.

15 M. Sydow, M. Owsianiak, G. Framski, M. WozniakKarczewska, A. Piotrowska-Cyplik, L. Lawniczak, A. Szulc, A. Zgola-Grzeskowiak, H. J. Heipieper and L. Chrzanowski, Ecotoxicol. Environ. Saf., 2018, 147, 157-164.

16 J. Suchodolski, J. Feder-Kubis and A. Krasowska, Microbiol. Res., 2017, 197, 56-64.

17 Y. Shao, Z. Du, C. Zhang, L. Zhu, J. Wang and J. Wang, Bull. Environ. Contam. Toxicol., 2017, 99, 213-217.

18 D. Liu, H. Liu, S. Wang, J. Chen and Y. Xia, Sci. Total Environ., 2018, 622-623, 1572-1580.

19 V. R. Thamke and K. M. Kodam, J. Hazard. Mater., 2016, 320, 408-416.

20 R. Biczak, B. Pawlowska, A. Telesinski and J. Kapusniak, Environ. Sci. Pollut. Res., 2017, 24, 18444-18457. 
21 X. Liu, C. Ji, Q. Yang, Z. Bao, X. Fan, Y. Yang and H. Xing, ACS Sustainable Chem. Eng., 2017, 5, 1974-1981.

22 D. Zhao, Y. Liao and Z. Zhang, Clean: Soil, Air, Water, 2007, 35, 42-48.

23 K. Fukumoto, M. Yoshizawa and H. Ohno, J. Am. Chem. Soc., 2005, 127, 2398-2399.

24 X. Wu, Z. Chen, Y. Li, Q. Yu, Y. Lu, Q. Zhu, Y. Li, D. An, J. Qi and W. Wu, Int. J. Pharm., 2019, 558, 380-387.

25 H. Prydderch, A. Haib, M. Spulak, B. Quilty, K. Kummerer, A. Heise and N. Gathergood, RSC Adv., 2017, 7, 2115-2126.

26 B. Yang, Q. Zhang, Y. Fei, F. Zhou, P. Wang and Y. Deng, Green Chem., 2015, 17, 3798-3805.

27 C. Chiappe, A. Marra and A. Mele, in Carbohydrates in Sustainable Development II, ed. A. P. Rauter, P. Vogel and Y. Queneau, Springer Berlin Heidelberg, Berlin, Heidelberg, 2010, pp. 177-195.

28 L. Bouchardy, V. Rodriguez-Ruiz, C. Bournaud, F. D. Boyer, M. Toffano, P. Judeinstein and G. Vo-Thanh, ChemistrySelect, 2018, 3, 958-962.

29 G.-h. Tao, L. He, N. Sun and Y. Kou, Chem. Commun., 2005, 3562-3564.

30 S. Kirchhecker and D. Esposito, Curr. Opin. Green Sustain. Chem., 2016, 2, 28-33.

31 Q.-P. Liu, X.-D. Hou, N. Li and M.-H. Zong, Green Chem., 2012, 14, 304-307.

32 Y. Qian, S. Xiao, L. Liu and Y. Wang, Tetrahedron: Asymmetry, 2008, 19, 1515-1518.

33 J. Zhang, S. Zhang, K. Dong, Y. Zhang, Y. Shen and X. Lv, Chem.-Eur. J., 2006, 12, 4021-4026.

34 O. B. Ghanem, N. Papaiconomou, M. I. Abdul Mutalib, S. Viboud, M. El-Harbawi, Y. Uemura, G. Gonfa, M. Azmi Bustam and J.-M. Leveque, J. Mol. Liq., 2015, 212, 352-359.

35 K. S. Egorova, M. M. Seitkalieva, A. V. Posvyatenko and V. P. Ananikov, Toxicol. Res., 2015, 4, 152-159.

36 X.-D. Hou, Q.-P. Liu, T. J. Smith, N. Li and M.-H. Zong, PLoS One, 2013, 8, e59145.

37 W. Gouveia, T. F. Jorge, S. Martins, M. Meireles, M. Carolino, C. Cruz, T. V. Almeida and M. E. M. Araujo, Chemosphere, 2014, 104, 51-56.

38 S. P. M. Ventura, R. L. F. de Barros, T. Sintra, C. M. F. Soares, A. S. Lima and J. A. P. Coutinho, Ecotoxicol. Environ. Saf., 2012, 83, 55-62.

39 M. Rebros, H. Q. N. Gunaratne, J. Ferguson, K. R. Seddon and G. Stephens, Green Chem., 2009, 11, 402-408.

40 M. Matzke, J. Arning, J. Ranke, B. Jastorff and S. Stolte, in Handbook of Green Chemistry, Wiley-VCH Verlag $\mathrm{GmbH} \&$ Co. KGaA, 2010.

41 C. Anna, P. Lourdes, C. Francesc, R. Isabel, M. Angeles and G. M Teresa, J. Colloid Interface Sci., 2011, 355, 164-171.
42 T. P. Thuy Pham, C.-W. Cho and Y.-S. Yun, Water Res., 2010, 44, 352-372.

43 P. Mester, M. Wagner and P. Rossmanith, Ecotoxicol. Environ. Saf., 2015, 111, 96-101.

44 T. Maeda, Y. Manabe, M. Yamamoto, M. Yoshida, K. Okazaki, H. Nagamune and H. Kourai, Chem. Pharm. Bull., 1999, 47, 1020-1023.

45 M. R. J. Salton and J. G. Pavlik, Biochim. Biophys. Acta, 1960, 39, 398-407.

46 A. D. Russell, J. Antimicrob. Chemother., 2003, 52, 750-763.

47 L. Myles, R. G. Gore, N. Gathergood and S. J. Connon, Green Chem., 2013, 15, 2740-2746.

48 S. P. M. Ventura, C. S. Marques, A. A. Rosatella, C. A. M. Afonso, F. Goncalves and J. A. P. Coutinho, Ecotoxicol. Environ. Saf., 2012, 76, 162-168.

49 F. J. Hernandez-Fernandez, J. Bayo, A. Perez de los Rios, M. A. Vicente, F. J. Bernal and J. Quesada-Medina, Ecotoxicol. Environ. Saf., 2015, 116, 29-33.

50 A. A. Salyers and D. D. Whitt, Microbiology: diversity, disease, and the environment, Fitzgerald Science Press, Inc, Bethesda, 2001.

51 G. M. Walker, Yeast physiology and biotechnology, J. Wiley \& Sons, Chichester, New York, 1998.

52 D.-J. Tao, Z. Cheng, F.-F. Chen, Z.-M. Li, N. Hu and X.-S. Chen, J. Chem. Eng. Data, 2013, 58, 1542-1548.

53 L.-S. Wang, L. Wang, L. Wang, G. Wang, Z.-H. Li and J.-J. Wang, Environ. Toxicol., 2009, 24, 296-303.

54 D. J. Couling, R. J. Bernot, K. M. Docherty, J. K. Dixon and E. J. Maginn, Green Chem., 2006, 8, 82-90.

55 C. Pretti, C. Chiappe, D. Pieraccini, M. Gregori, F. Abramo, G. Monni and L. Intorre, Green Chem., 2006, 8, 238-240.

56 S. Stolte, M. Matzke, J. Arning, A. Boschen, W.-R. Pitner, U. Welz-Biermann, B. Jastorff and J. Ranke, Green Chem., 2007, 9, 1170-1179.

57 J. Ranke, S. Stolte, R. Stormann, J. Arning and B. Jastorff, Chem. Rev., 2007, 107, 2183-2206.

58 H. Liu, S. Zhang, X. Zhang and C. Chen, J. Hazard. Mater., 2015, 286, 440-448.

59 R. Biczak, B. Pawlowska, P. Balczewski and P. Rychter, J. Hazard. Mater., 2014, 274, 181-190.

60 R. G. Gore, L. Myles, M. Spulak, I. Beadham, T. M. Garcia, S. J. Connon and N. Gathergood, Green Chem., 2013, 15, 2747-2760.

61 P. H. Howard, R. S. Boethling, W. Stiteler, W. Meylan and J. Beauman, Sci. Total Environ., 1991, 109-110, 635-641.

62 R. S. Boethling, P. H. Howard, W. Meylan, W. Stiteler, J. Beauman and N. Tirado, Environ. Sci. Technol., 1994, 28, 459. 